been made to me: "What wonderfully fine scales you must have to weigh atoms!" To-right I have endeavored to point out that the purely chemical work, which precedes the introduction of the substance into the balance-case, is far more important than the mere operation of weighing. Moreover, speculation and the higher mathematics are as yet of little service to us in this quest; I cannot help thinking that any ultimate general conclusion must rest upon careful laboratory work. Chemistry is still largely an inductive science; when we have discovered the realities, we shall be in a position to attempt to explain them. In the meantime more accurate values, discovered little by little through patient investigation, will be of use to the thousands of men throughout the world who daily employ these fundamental data of chemistry.

This method of working is very different from that of the great man whose memory we are celebrating to-night. Willard Gibbs went always from the abstract to the concrete; his whole point of view was deductive rather than inductive. Perhaps herein we may find one reason why his extraordinary generalizations have so often remained hidden until other investigators have come upon them inductively. Nevertheless, the radical difference of method brings with it no real contradiction of aim and outcome. The mathematical logic of Gibbs supplements but does not supplant the work in the laboratory; both have the same object, and each helps the other toward the ultimate goal. This goal-a more fundamental understanding of the mechanism of the universe in which our lot is cast-is worthy of the highest endeavor of mankind.

\title{
COMPRESSIBILITIES OF CERTAIN HYDROCARBONS, ALCOHOLS, ESTERS, AMINES, AND ORGANIC HALIDES.
}

By TheOdore W. Richards, W. N. Stuld, J. H. Mathews and C. I. Speyers.

Received April 27, 1912.

\section{Introduction.}

In previous papers from this laboratory the compressibilities of certain inorganic compounds as well as of a number of the elementary substances have been discussed: ${ }^{1}$ It has been demonstrated that compressibility is a property having chemical relations of importance; and accordingly it becomes a matter of interest to compare the compressibilities of a wide variety of organic substances. Unfortunately, however, the existing data concerning this subject are incapable of throwing light upon it be-

${ }^{2}$ Richards and Stull, Pub. Carnegie Inst., 7 (1903); Z. physik. Chem., 49, I (1904); Richards, This Journal, 26, 399 (1904); Richards, Stull, Brink, and Bonnet, Pub. Carnegie Inst., 76 (1907); Z. physik. Chem., 61, 77 (1907); Ibid., 6I, I83 (1907); THIS Jourval, 3 1, r54 (1909); Richards and Mathews, Ibid., 30, 8 (1908); $Z$. phisit. Chem., 6I, 449 (19 8); Richards and Jones, This Journal, 31, I58 (1909); $Z$, physik. Chem., $71,5=1910$. 
cause no uniformity as to temperature or range of pressure exists among them. Compressibility is very greatly affected by both these conditions; hence it was clear that a completely new set of data was needed. The present paper contains a description of a research intended to supply, in part, this lack.

In this research it seemed more useful from a chemical standpoint to make determinations involving the moderate compression of a large variety of substances which show systematic relationships between their composition and structure, rather than to investigate only a few substances over a very wide range of pressure. The new method which has been used in the Chemical Laboratory of Harvard College lends itself very satisfactorily to the former problem. The latter problem, which requires more cumbrous apparatus, has been independently taken up by P. W. Bridgman, of the Jefferson Physical Laboratory of Harvard University.

As will be seen, many interesting relations are to be noted between the compressibilities of organic substances; and these relations afford valuable clues to the causes of other properties of the substances in question. The full discussion of the results, especially in relation to the theory of compressible atoms, is reserved for another paper. The present chapter deals with the presentation of the experimental data and the most obvious relationship between them. It may be said in passing, however, that the outcome is decidedly favorable to the theory.

\section{The Pressure Gage.}

Adequate means of measuring the pressure is one of the essential features in any work upon compressibility. In previous work from this laboratory, wherein the relative compressibilities alone were desired, the absolute accuracy of the gages employed was a matter of minor import, provided only that these instruments were constant in their indications. Constancy was proved from time to time by reference to the compressibility of a standard substance, water, which gave sufficiently consistent results and showed that the gages were to be depended upon within a small limit of error. The present work, however, aimed to secure results not only accurate relatively to one another but also possessing a precision more nearly final. If the absolute compressibilities of water and mercury had been known with great precision, they could have been used to calibrate the gage; but unfortunately at that time both these values were in doubt. Accordingly it was necessary to verify the readings of the gages by means of some satisfactory standard instruments. Fortunately such an instrument had just been constructed by the Physical Laboratory of Harvard University, by Dr. Bridgman, who very kindly permitted us to use it in verifying one of our gages, No. 3,0r4,49r (designated later as Gage B), made by Schaeffer and Budenberg. Bridgman's ingenious 
apparatus is somewhat similar in principle to that used by Amagat, but is simpler and more satisfactory in its operation. Since it has been fully described by him, ${ }^{1}$ it is necessary to mention here only the fact that the gage consists of a freely moving small piston of accurately measured diameter, provided with a carriage for carrying very heavy weights. The diameter of the piston was found to be 0.2506 inch by means of two Brown and Sharp micrometer-calipers, which gave identical results. This figure was probably accurate to within one unit in the last decimal place. The cylinder in which the piston moved was almost exactly 0.000 I inch larger in diameter as nearly as could be determined with the help of other pistons of slightly larger size, hence there was only a very slight leakage around the cylinder. This was diminished at high pressures by a very ingenious device explained by Bridgman, and the diminution . of diameter of the piston under pressure was shown by him to be negligible as far as our work is concerned. From these data the area of the crosssection of the cylinder was taken to be $0.3185 \pm 0.0002$ square centimeters. Each weight used was carefully calibrated. The largest sum total of weights ever needed (that demanded by the pressure indicated on the hydraulic gage as $557.5 \mathrm{~kg}$. per square centimeter) was $177.1 \mathrm{~kg}$., a weight corresponding to a pressure of $556.0 \mathrm{~kg}$. per square centimeter. Thus at this point this hydraulic gage gave a reading 1.5 units too high, and this quantity must always be subtracted from the observed reading in order to obtain the true pressure. Gage B and Bridgman's standard were thus compared at short intervals of about Io atm. twice throughout the interval between 50 and 550 atm., a process which demanded nearly one hundred adjustments. Especial pains were taken about the points near 100,300 , and $500 \mathrm{~atm}$., as these were the most important in their bearing upon the data desired. The two parallel series of measurements agreed very well with one another, rarely differing from the mean by an amount greater than the limit of the error of reading the gage ( 0.5 atm.). Hence the curve taken from the average of the two probably gives the errors of the gage with exactness. This curve for Gage $B$ is plotted as the heaviest line in the accompanying diagram, in which each

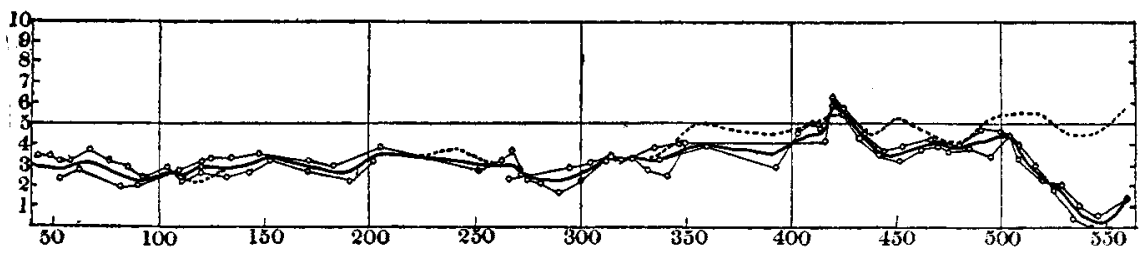

Fig. I.--Errors of gage. Gage readings are plotted as abseissas, errors of gage are plotted as ordinates. The black line indicates "Gage B, used for most of the work; the dotted line indicates Gage A.

'Bridgman, Proc. Am. Acad., 44, 201 (rgog). 
small circle represents a comparison of the gages and the two fine zigzag lines indicate the two series of measurements. Another gage, No. 2,740,74I (Gage A), used in some of the earlier work, was standardized by comparison with Gage B. ${ }^{1}$ In many cases A and B agreed; where A deviated from $B$ the indications of the former are marked on the diagram with a heavy dotted line.

It will be seen that both the gages throughout their length gave somewhat too high readings, except Gage $B$ at the 550 point. The errors average about 4 atm., sinking to 2 at the 90 and 290 points, and rising to almost 6 toward the higher pressures.

An appropriate correction thus indicated was applied to each reading recorded in the following series of observations during which Gage B alone was used. The consequence of these errors of the gages was usually to make the uncorrected compressibility of each substance at high pressures appear to be somewhat less than it really was.

The general tendency from this cause affects also all previous work done in this laboratory, except that done with Gage B above 5 Io atm.; but fortunately the effect is in no case large, and the conclusions based upon the results are not affected in the least degree. Nevertheless, it is a matter of interest to evaluate accurately the effect of the errors of the two gages upon the work already published (which all depended upon either one or the other of them), if only to show that this effect was unimportant. This will be done in the near future, when it will be shown that the constant results obtained from the standard substance water proved the readings of the gages to have been thoroughly concordant over a long term of years. Incidentally it may be mentioned that the substitution of Bridgman's new value for the compressibility of mercury (3.90 in terms of $\mathrm{kg}$. per square centimeter), instead of the old value, (3.7 I based largely on the work of Amagat) causes a far greater change in the calculated compressibilities of the metals than were caused by the small errors in our pressure gage.

\section{The Piezometer and Device for Measuring the Change of Volume.}

The method used for the determination of compressibility consisted in the determination of the difference between the compressibility of each substance in question and that of mercury, which is assumed to be known. By adding to the difference as determined by experiment the compressibility of mercury, the compressibility of the substance is obtained.

The apparatus necessary has already been described more than once in detail. It consists in the first place of a piezometer of glass, which is first wholly filled with mercury and subjected quantitatively to pressure, and then afterwards partly filled with the liquid in question (displacing an equal volume of mercury) and again subjected to quantitative com-.

' Pub. Carnegie Inst. of Washington, 76, 12 (1906). 
pression. The diminution of volume was determined by allowing the mercury to make contact with a very finely pointed platinum wire, the changes in volume being measured by weighed globules of mercury. Thus the difference between the compressibility of the substance and that of mercury may be determined very simply from the difference between the two parallel series of compressions; and the compression of the apparatus is entirely eliminated from the result, occurring equally in the two series.

Various forms of apparatus, all depending upon the same principle, have been suggested for this purpose. ${ }^{1}$. In the present work twelve different piezometers were used of several different volumes and patterns, five having been used by Mathews, four by Stull and three by Speyers. These are designated as M.I, M.2, M.3, M.4, M.5, St.I, St.4, St.6, St.7, Sp.I, Sp.2, Sp.3. Of these that called St. I was of the form originally suggested for liquids, ${ }^{2}$ except that it had no stopcock above, but was filled through the tube containing the platinum wire. The jacket designated as St.4 was essentially of the type shown on page 12 of the same paper, although slightly different in shape. All the other piezometers were of the form shown in a subsequent paper ${ }^{8}$ from this laboratory as well as in the accompanying illustration. The hollow stopper of each of these latter piezometers was filled with mercury in order to increase its weight and diminish the danger of displacement during a determination. The stop- . pers were all securely held in place by means of stout thread or pliable string.

In most of these instruments the substance to be studied was directly introduced into the piezometer itself, but in four cases, namely, M.5, St.4, Sp.2 and Sp.3, the liquid was contained in a little inverted cigar-shaped tube or bulb, closed at the top and open below to the mercury. In the two former of these cases the bulb was provided with a bail like a bucket which was hooked into a small hook of platinum, fused into the bottom of the glass piezometer. This was to hold the tube down and prevent it from being pressed against the upper part of the instrument by the buoyant effect of the mercury. In the piezometers designated as Sp.2 and Sp.3, the bulb had no bail and was not Fig. 2. - The

${ }^{1}$ Carnegie Institution of Washington Publications, $7,76$.

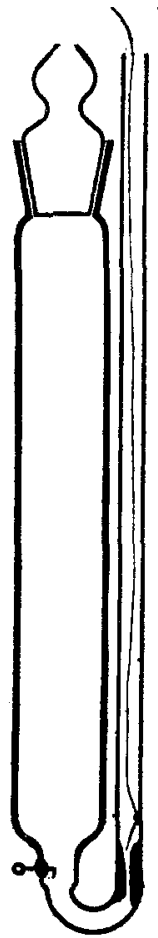

${ }^{2}$ Carnegie Publication, 7, r7. A slight modification of this form has been used very successfully by $\mathrm{V}$. W. Eckman in determining the compressibility of sea water. (Pub. de Circonstance, 42, Lab. Centr. à Christiana, Nov., 1908), but his change seems to present little if any advantage.

s Carnegie Publication, 76, II, Jacket V. 
hooked to the bottom, but was provided with a pointed top so that it should press only in one very small spot on the stopper. This arrangement was found to exclude the objectionable fine cracks between glass surfaces as eflectually as the other arrangement. In each case the instrument was first tested with everything in place, filled with mercury alone.

The choice of one or the other of these piezometers was really immaterial except as a matter of convenience in manipulation, for all gave the same results under the same conditions. This was easily proved by making experiments upon water, which was chosen as a standard substance; these were sufficiently concordant to show that not only the gages but also the piezometers were capable of giving consistent results in every case.

The weights of liquids employed were determined in slightly different fashion according to the shape of the piezometer, but wherever possible these weights were verified by being determined twice, first by loss of weight in a pipet or receptacle used to deliver the liquid into the piezometer, and secondly by the change in weight of the piezometer, making due allowance of course for the mercury displaced and taking especial pains to keep the temperature constant. It is especially important thus to verify the weights taken. All the other data concerning the experiment check one another in such a way that a false result is almost impossible; but a mistake in the original weighing of the material could not be detected, and would vitiate every part of the experiment in which it occurred. All weights and all densities (taken in the usual manner at $20^{\circ}$ by means of the Ostwald-Sprengel pycnometer) were reduced to the vacuum standard.

After successive drops of mercury had been added to the piezometer and the corresponding pressures noted, it was always the custom to remove and weigh again most of the added mercury, and to test once more the pressure needed just to make the electrical contact. Thus it may be determined whether or not the piezometer or its contents have suffered a permanent change of volume during the compression to which it has been subjected. Small mercury pipets ${ }^{1}$ with exceedingly long drawnout fine jets serve conveniently to add and to remove mercury. As a rule no change in the volume of the system was perceptible. Clearly even in those few cases where a slight diminution in the volume of the piezometer was actually found (as indicated by a final pressure slightly too high to correspond to the original reading), this small change in volume was to be referred to the forcing in of the stopper during the experiment and not to any permanent hysteresis of the glass. In general, the elimination of the glass joint is desirable where possible, but with care it may

${ }^{1}$ See Ostwald-Luther, Physik. chem. Messungen, I66 (1910). 
nevertheless be made to serve well. Much depends upon the accuracy of the grinding and the care used in distributing the lubricant and pressing the stopper into place. If the stopper should have been further pressed in during the experiment, it is evident that the final pressure, found after taking out mercury, should be taken as the true lower pressure in plotting the curve. We have since found glass to exhibit distinct temporary hysteresis even at $300 \mathrm{~atm}$. but this hysteresis is eliminated in the calculation, because its effect is the same in the blank run with mercury alone as when the substance under investigation is present. ${ }^{1}$

\section{The Temperature Adjustment.}

All the work described below was strictly isothermal; and much depends upon keeping the temperature perfectly constant. This was accomplished by means of a carefully constructed thermostat, which was able to keep the temperature constant to within $0.002^{\circ}$ for an indefinit period. The form employed has given good service for about ten years, having been essentially unchanged since 1903 (except for the substitution of a large spiral heating coil for an incandescent heating lamp in 1907). ${ }^{2}$ A somewhat similar thermostat has recently been very fully described by Hulett, and has evidently given satisfaction in his hands also. His apparatus is said to keep the temperature constant to within $0.010^{\circ}$; his less degree of constancy was probably due to the fact that his mercury surface was not protected as ours was by a hydrogen atmosphere, and perhaps also because of less violent agitation of the water in the bath and less constant room temperature.

The thermometers used in determining the temperature were glass thermometers of excellent quality. To discover possible variations in the thermostat a Beckman thermometer, capable of being easily read to within the thousandth of a degree, was used; and the necessary allowances were made for changes in the atmospheric pressure. The absolute temperature of the bath was fixed by careful comparison with Baudin thermometers standardized by the Bureau des Poids et Mesures at St Cloud. Great constancy of temperature is more important than a very precise knowledge of the absolute temperature, but all the determinations described in this paper were made within a few hundreths of a degree of the true $20^{\circ}$ on the hydrogen standard.

\section{The Apparatus for Compression.}

The piezometer was compressed in the steel barrel of the well known excellent high pressure pump, manufactured by the Sociéte Genevoise. The barrel was half filled with mercury and the rest with a clean, rather

1 Richards and Shipley, results as yet unpublished.

${ }^{2}$ Richards and Stull, Pub. Carnegie Inst., 7, I3 (1903); Ibid., 76, 9 (1907); Richarris, Wilson and Garrod-Thomas, Pub. Carnegie Inst., II8, I6 (1909). 
viscous mineral oil. ${ }^{1}$ The piezometer was suspended from the bronze cap provided with the instrument by means of two stout brass hooks screwed into its lower surface. The electrical connection was made by means of an insulated wire running through the center of a glass tube cemented into the bronze cup. The barrel was immersed in the thermostat as usual; if the temperature of the room is far different from that of the bath, the immersion must be complete, and none of the screw cap may be allowed to protrude above the water.

\section{Purification of Materials.}

Most of the materials used came originally from one or the other of two important German manufacturers of chemicals. They were the purest which these firms furnished, but they often were by no means satisfactory. They were all repeatedly distilled fractionally, and of most of them it could be said at least that the largest fraction distilled in the neighborhood of the reputed boiling point of the compound in question. Especial pains was taken with the xylenes, of which the specimens provided by Kahlbaum were distinctly the best. These were many times distilled and the paraxylene was repeatedly crystallized until its freezing point became constant at $13.2^{\circ}$. The distillation was in many cases conducted by electrical heating through a coil immersed in the liquid. ${ }^{2}$

The paraffin hydrocarbons were all prepared synthetically at Harvard by Latham Clarke, or under his supervision, especially for this research. We take pleasure in thanking Dr. Clarke for having given his time to this work. The somewhat heavy expenses involved in providing the raw material were borne by the Carnegie Institution of Washington. The first of these was the isohexane, prepared by Clarke in the summer of 1905. Not long afterwards Dr. J. E. Zanetti kindly gave his time to the work of preparing the normal hexane. The octanes were all made more recently after the methods had been perfected by Clarke, and showed a high degree of purity, as indicated by the range of the boiling point. ${ }^{3}$

Two samples of ethylbenzene with slightly different properties were investigated. Evidently one or the other or both still contained impurities, although both were many times fractionally distilled. Further experiments with ethylbenzene will be instituted to decide between the slightly differing results for its compressibility.

The glycol also was made by Clarke from dibromoethane during the summer of 1905 . He used the method of Haworth and Perkin, and the product was fractionated until it all distilled within $0.3^{\circ}$.

${ }^{1}$ More recently, the personally c mmunicated suggestion of the Earl of Berkeley has led us to substitute castor oil, which is better in several respects.

${ }^{2}$ Richards and Mathews, Proc. Am. Acad., 43, 52 I (1908); This Journal, 30, I282 (1908); $Z$. physik. Chem., 64, I20 (1909).

Latham Clarke. 
The organic halogen compounds were all made in this laboratory from fairly pure materials and were repeatedly distilled, as were the other substances.

In all cases the densities and boiling points must be relied upon as the chief evidence of purity, as it is far from easy to detect similar organic substances in the presence of one another. For the present purpose these two criteria are especially suitable, because, as a general rule, substances with like boiling points and densities have also like compressibilities. Thus impurities having these properties in like measure would do no harm, as far as the comparisons to be instituted later are concerned.

The mercury was purified by usual methods, zinc and other more soluble metals being separated by treatment with dilute nitric acid or standing under concentrated sulphuric acid, and metals of higher boiling point being eliminated by distillation.

\section{Calculation of Results.}

Having discussed the experimental determination of the four essential conditions: pressure, volume, temperature and purity of material, we may turn to the calculation. It is convenient to plot all the results with great care by means of a spline, and to take from the curves the weights of the respective additions of mercury which correspond to definit pressure intervals, for example, 100 or $200 \mathrm{~atm}$. of pressure. This plotting is facilitated, and the results are more accurate, if the actually observed points are so placed as to correspond nearly to initial and final points of these intervals, for example, 100, 200, 300, 400 and 500 atm. It is highly advantageous to verify the values taken from the curves by arithmetical interpolation, which is more accurate than the curves unless these are drawn on a very large scale.

Instead of choosing successive pressure limits at every hundred atm., intervals of $200 \mathrm{~atm}$. were employed in the present research because the larger intervals reduced the probable error of the result. The least accurate part of the work is the reading of the pressure on the Bourdon gage employed, hence increasing the pressure range increases the percentage accuracy.

In formulating the calculation, we have to do here only with the simplest case, because only one substance beside mercury was present. The difference between the weights of added mercury needed when the investigated substance is present and that when mercury alone is present, over a given pressure range, evidently corresponds to the difference between the changes of volume over that range. To translate weights of mercury into volume changes, the former must be divided by the density of the mercury under the highest pressure. Thus the expression for the difference between the volume change of the investigated substance and that of an equal bulk of displaced mercury is 
980 T. W. RICHARDS, W. N. STULL, J. H. MATHEWS AND C. L. SPEYERS.

$$
\frac{\left(w-w^{\prime}\right)\left(\mathrm{I}-\mathrm{P}_{1} \beta^{\prime \prime \prime}\right)}{\mathrm{I} 3.546}=\Delta \mathrm{V}
$$

where $\beta^{\prime \prime \prime}$ signifies the average compressibility of mercury between $O$ and $\mathrm{P} ; w$ and $w^{\prime}$ signify the two weights of mercury obtained in the two series of experiments, corresponding to the pressure range $P_{1}-P_{2}$; $P_{1}$ is the highest pressure; 13.546 is the density of mercury at $20^{\circ}$ and atmospheric pressure; and $\Delta \mathrm{V}$ is the difference in the volume changes of the substance and a like volume of mercury over the same pressure ranges.

The compressibility of the substance is hence calculated by dividing $\Delta V$ by the original volume of substance $W / D$ and by the pressure interval $\left(\mathrm{P}_{1}-\mathrm{P}_{2}\right)$, and then adding to the result the known compressibility of mercury. Thus

$$
\beta=\frac{\left(w-w^{\prime}\right)\left(\mathrm{I}-\mathrm{P}_{1} \beta^{\prime \prime \prime}\right) \mathrm{D}}{\mathrm{I} 3.546 \mathrm{~W}\left(\mathrm{P}_{1}-\mathrm{P}_{2}\right)}+\beta^{\prime}
$$

in which the newly introduced letters have the following significance:

$\beta=$ average compressibility of the investigated substance between $\mathrm{P}_{1}$ and $\mathrm{P}_{2}$.

$\beta^{\prime}=$ average compressibility of mercury between $P_{1}$ and $P_{2}$.

$\mathrm{P}_{2}=$ the lower limit of the pressure range.

$\mathrm{D}=$ the density of the substance at $20^{\circ}$.

$\mathrm{W}=$ the weight of substance taken. ${ }^{1}$

This expression may be much simplified, if a given pressure range (e. g., 100-500) is always used. Thus in this case the equation becomes

$$
\beta_{100-500}=\frac{\left(w-w^{\prime}\right) \mathrm{D}}{\left(\mathrm{I} 3.57^{2} \mathrm{~W}\right) 400}+\beta_{100-500}^{\prime} .
$$

If the result is calculated in several stages, as for example, over the ranges 100-300 atm. and 300-500 atm., account must be taken of the fact that the density of mercury increases with the pressure, if the greatest accuracy is desired. Thus under 300 atm. mercury at $20^{\circ}$ has a density of 13.562 , and the expression over the range $100-300$ becomes

$$
\beta_{100-300}=\frac{\left(w-w^{\prime}\right) D}{(13.562 \mathrm{~W}) 200}+\beta_{100-300}^{\prime} .
$$

The compressibility over the range $300-500$ is then most conveniently found by means of the following obvious equation:

$$
\beta_{300-500}=2 \beta_{100-500}-\beta_{100-300} .
$$

An example will, perhaps, make the matter clearer. Let us take, for instance, the work on the first substance given in the table below: 2.409 grams of normal hexane in piezometer St.4 gave as the corrected

1 In a recent paper, Ekmann (loc. cit.) criticized one detail of this calculation; but since that time in a very friendly personal letter he has entirely withdrawn his criticism. 
pressure at the moment of electrical contact $73.0 \mathrm{~kg}$. per square centimeter. On adding $690 \mathrm{mg}$. of mercury, the pressure was 175.5 . On adding further $688 \mathrm{mg}$., the pressure rose to 293.5 ; again, $680 \mathrm{mg}$. more caused a further rise in pressure of $135.5 \mathrm{~kg}$. per square centimeter and finally when $365 \mathrm{mg}$. more of mercury had been added, the total pressure needed was 509.5. There were now present in all 2.423 grams of added mercury; and when 2.188 were removed, leaving only $235 \mathrm{mg}$. behind, the pressure fell to 106.5. By algebraic interpolation or from a curve it is easy to find that the weights of mercury added between the pressure values IOO and 300 must have been $1223 \mathrm{mg}$. and that between Ioo and 500 must have been $219 \mathrm{Img}$. The piezometer (St.4) when filled with mercury alone gave I 44 and $225 \mathrm{mg}$., respectively, over these same ranges. The differences thus become I I09 and I966, respectively. Substituting these two values for $w-w^{\prime}$ in the appropriate equations above:

$$
\begin{aligned}
& \beta_{100-300}=\frac{1109 \mathrm{D}}{2712.4 \mathrm{~W}}+\beta^{\prime}{ }_{100-300} \\
& \beta_{100-500}=\frac{1966 \mathrm{D}}{5429 \mathrm{~W}}+\beta^{\prime}{ }_{100-500}
\end{aligned}
$$

The constant $\mathrm{D} / \mathrm{W}$ appearing in both equations is 0.27376 . Hence

and

$$
\beta_{100-300}=\text { III.9 }+\beta_{100-300}^{\prime}=\text { II5.8 }
$$

Hence,

$$
\beta_{100-500}=99.14+\beta_{100-500}=103.04 \text {. }
$$

$$
\beta_{300-500}^{\prime}=2(103.04)-115.8=90.3 .
$$

The results thus obtained are expressed in terms of the kilogram per square centimeter as the pressure unit, because that was the standard used in measuring the pressure. Upon multiplying the results by I.02 they may be converted into compressibilities expressed in terms of the megabar ${ }^{1}$ or "megabarie;" or by multiplying by I.033 they may be converted into results in terms of ordinary "atmospheres." One must remember, however, that the numbers thus obtained no longer correspond to the pressure ranges $100-300$ and $300-500$ pressure units. If the transformation is made into megabars, the pressure ranges to which the results correspond are then 98-294 and 294-490 megabars, or if the conversion is into atmospheres, the pressure ranges are about $97-290$ and $290-$ 484 atm., respectively. If the compressibilities remained constant over the whole range specified, this matter would be of no importance, but because the compressibility of every substance diminishes as the pressure rizes, the especial range to which the values correspond is not wholly negli-

${ }^{1}$ Carnegie Institution of Washington, Publication 7,$43 ; Z$. physik. Chem., 49, 9 (I904). 
gible; and it becomes more important as the falling off of compressibility with pressure increases. ${ }^{1}$

The recalculation of the results for kilograms per square centimeter in order to correspond to the ranges included between the round numbers 100-300 and 300-500 megabars or atmospheres is not a simple matter. It is most conveniently done by marking off on the curves (including the curves for the compression of the piezometers filled with mercury alone) the new appropriate points, and recalculating the results anew from these data. Thus the results in megabars are obtained by marking the points on the curve corresponding to $102.0,306.0$ and $510.0 \mathrm{~kg}$. per square centimeter, computing the change of volume between these pressures, and in making the calculation these pressure ranges would each be called 200 megabars, for the megabar is $1.020 \mathrm{~kg}$. per square centimeter. The corresponding procedure would be used for converting the resilts into terms of atmospheres. Various other methods of approximation may be employed, taking into account the forms of the curves, but these need not be mentioned in detail. The results are tabulated further on in terms of megabars, the most logical and scientific of all the standards of pressure. It seemed hardly worth while to take the space for printing the results also in terms either of the kilogram per square centimeter or the arbitrary "atmosphere" because neither is very far from the megabar, which lies between the two, and equals the pressure of $75.015 \mathrm{~cm}$. of mercury at $45^{\circ}$ latitude. The data for hexane, given above, when recalculated in terms of megabars, gives 107.5 and 9r.4 (each multiplied by $\left.\mathrm{IO}^{-6}\right)$ for the compressibility over the pressure ranges roo-300 and $300-$ 500 , respectively.

There follow first the significant data concerning the piezometers alone and then those of a number of determinations with various substances, the results calculated from these data being given in a subsequent table.

Constants for the Severat Piezometers.

(The weights of mercury needed by them over definit pressure ranges, when full of mercury.)

Pressure ranges in megabars; weights of mercury in grams.

$\begin{array}{ccccccc}\begin{array}{c}\text { Pressure } \\ \text { ranges. } \\ \text { Megabars. }\end{array} & \text { M.1. } & \text { M.2. } & \text { M.3. } & \text { M.4. } & \text { M.s. } & \text { St.1. } \\ \text { I00-300 } & 0.0423 & 0.054 & 0.0730 & 0.0626 & 0.069^{2} & 0.078 \\ \text { I00-500 } & 0.083 \mathrm{I} & 0.107 & 0.1 .440 & 0.1238 & 0.138 \mathrm{I} & 0.154 \\ & \text { St.4. } & \text { St.6. } & \text { St.7. } & \text { Sp.1. } & \text { Sp.2. } & \text { Sp.3. } \\ \text { I00-300 } & 0.116 & 0.037 & 0.042 & 0.200 & 0.115 & 0.189 \\ \text { I00-500 } & 0.229 & 0.073 & 0.08 \mathrm{I} & 0.396 & 0.227 & 0.376\end{array}$

1 This point was not heeded in previous communications, because in most cases the correction did not exceed the probable error of the results. It becomes important when working with substances as compressible as the paraffin hydrocarbons and some of the esters, discussed in the present paper. 
The abbreviations, M., St., and Sp., designate the three collaborators named in the title, and indicate the experimenter in each case.

The capacity (or internal volume) of the piezometers may be inferred with sufficient precision from the amount of mercury which had to be added over the range 100-500 megabars. 0.1000 gram of mercury added in this way signified that the piezometer when full contained about $\mathrm{I} 72.5$ grams, or $12.74 \mathrm{cc}$. of mercury. Thus the piezometer St. 6 (the smallest) had a capacity of $9.28 \mathrm{cc}$. and Sp.I (the largest) had a capacity of 50.5 cc. The values in the table above must be multiplied by the appropriate factors (0.980 or IOI.3, respectively) if the calculations are performed intterms of $\mathrm{kg} . / \mathrm{cm}^{2}$. or atmospheres.

Some idea of the degree of accuracy which may be attained in these determinations may be obtained from the comparison of the results of parallel experiments-for example, No. 6 and No. 7, concerning symmetrical diisopropyl, these two having been made with different piezometers and different portions of the same substance. In the first of these two determinations, the compressibility over the range 100-500 megabars, calculated from the observed data, is found to be 94.7 ; in the second, 94.5 ; or on the average, 94.6. Over the shorter ranges 100-300 and 300500 the agreement is of the same order, the values being I04.9 and I04.6, on the one hand, and 84.5 and 84.6 , on the other, respectively. These were among the later and more satisfactory determinations; the earlier ones were less concordant. In general, because successive readings in a single determination check one another by their places on the curve, a duplication of this sort was not often practised.

The present research furnished data for the compressibility of fortyseven substances, and, if we include water and mercury (both having been quite as accurately studied as these) and bromine, chloroform, bromoform and carbon tetrachloride, taken from earlier work, fifty-three series of data are at hand, obtained under similar conditions and over like ranges of temperature and pressure. This somewhat extensive array of data enables one to generalize with more confidence than has heretofore been the case concerning the quantitative relations of the compressibilities both among themselves and in relation to other properties.

The most obvious relationship among the figures is perhaps that which pertains to the falling off of compressibility with increasing pressure. In a previous communication, ${ }^{1}$ the following statement is published: ".... one may infer: other things being equal, the greater the compressibility, the greater is its percentage decrease with increasing pressure. That other circumstances influence this relation is shown, however, by the fact that chloroform and carbon tetrachloride manifest different second differential quotients, although their first differential quotients

${ }^{1}$ Richards, Carnegie Institution of Washington, Publication 7, 44. 
984 T. W. RICHARDS, W. N. STULL, J. H. MATHEWS AND C. L. SPEYERS.

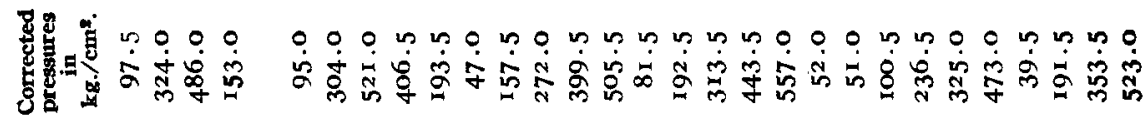

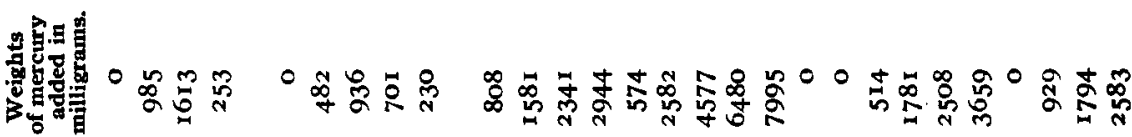

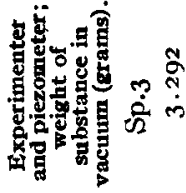

ڤें

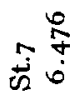

党

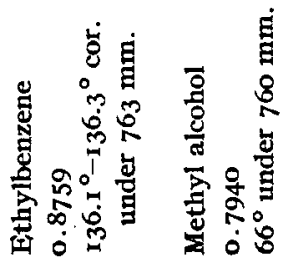

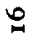

=

$\stackrel{\infty}{\sim}$

$\because$

(n)

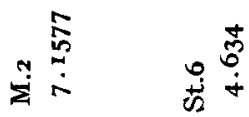

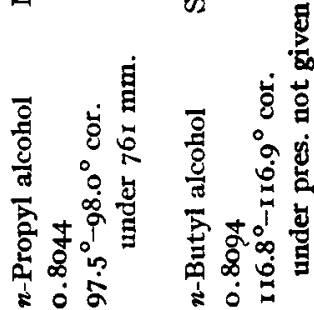

要 离高

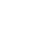

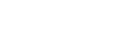

2

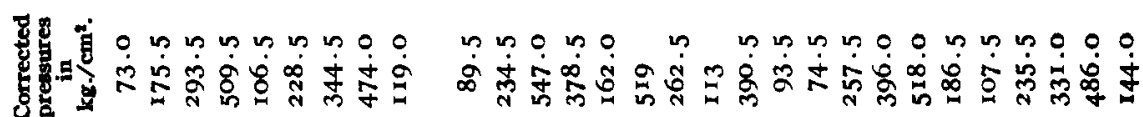

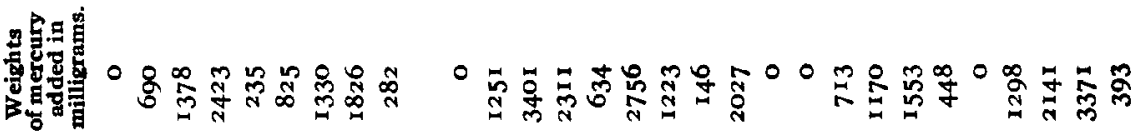

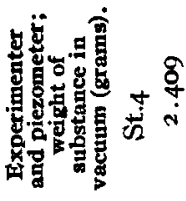

䒾

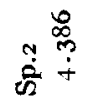

ㅎํำ

ชิ

के

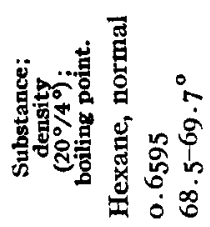

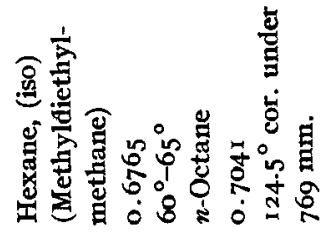

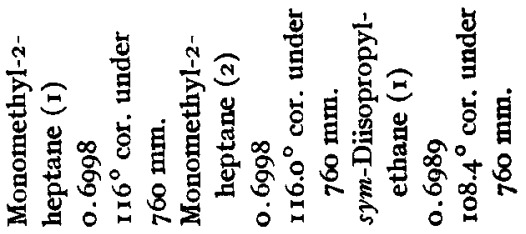

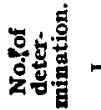


nn n n p n n n n

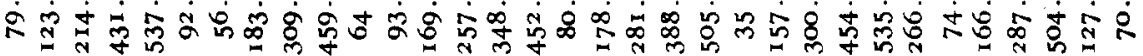

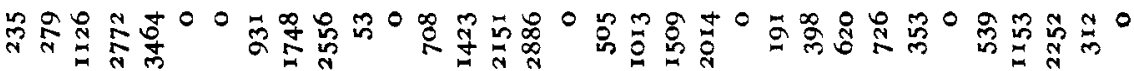

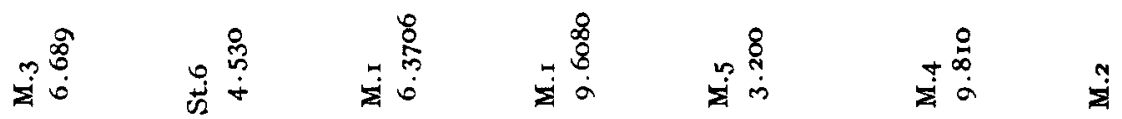

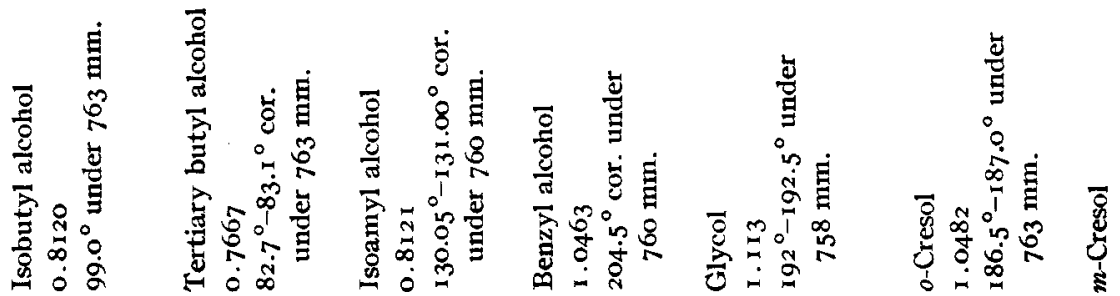
ริ $\ddot{4}$

ล

m

+

$\stackrel{4}{*}$

ְִ

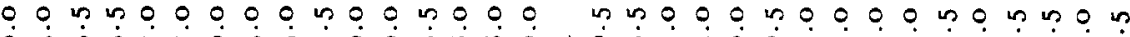

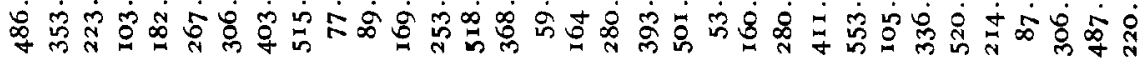

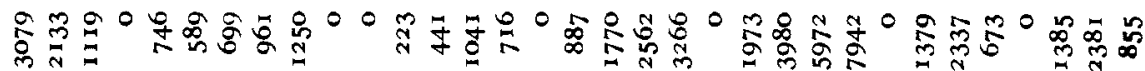

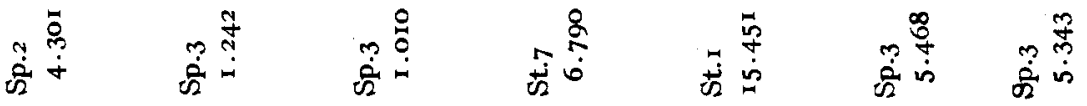

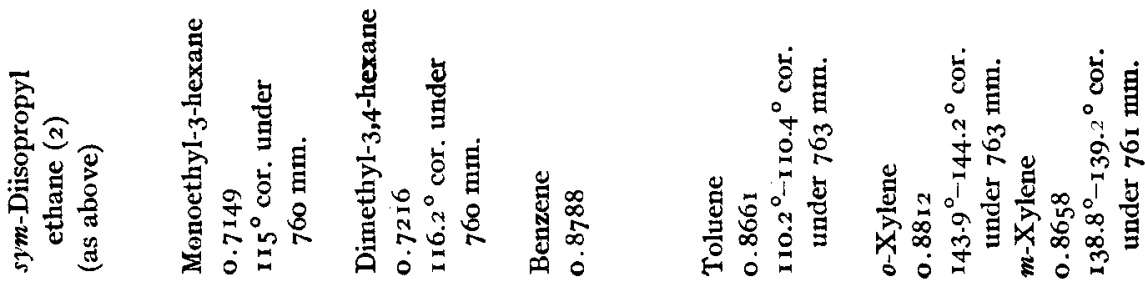

N

$\infty$

$a$

용

$=$

$\approx . \quad m$ 


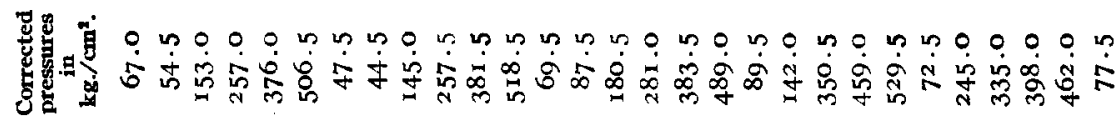

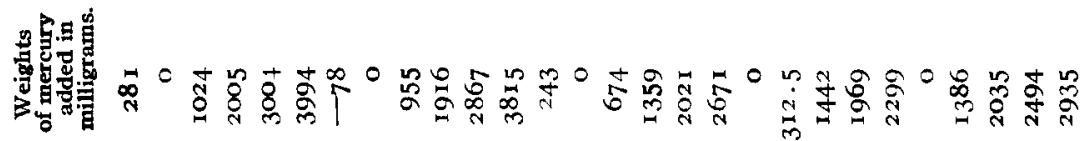

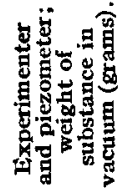

$\stackrel{\sim}{\stackrel{m}{n}}$

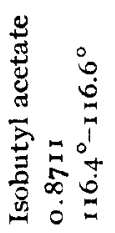

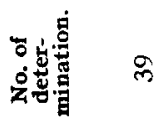

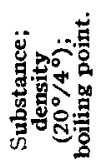

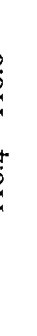

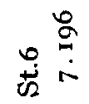

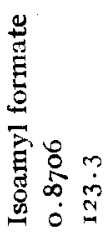

q

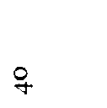

串总

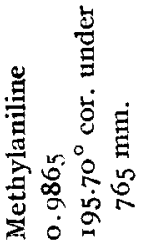

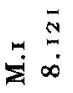

$\sum_{i=1}^{N}$

$\stackrel{m}{3}$

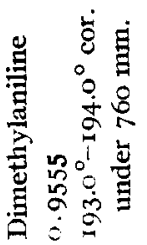

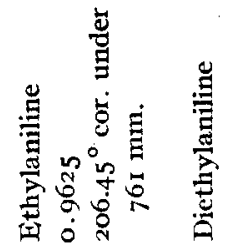

7

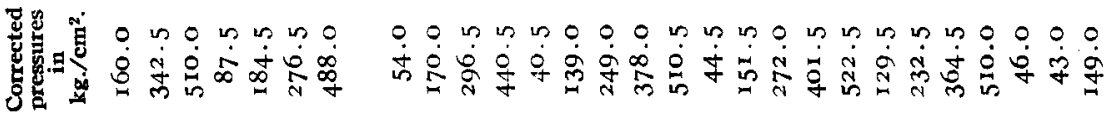

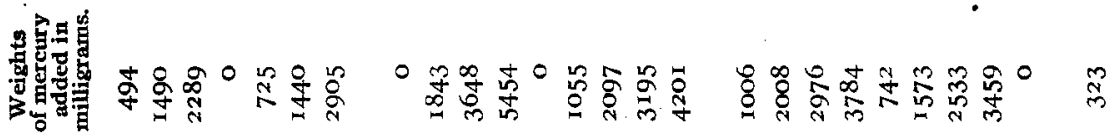
竜富<smiles>C1C[Ge]C1</smiles>

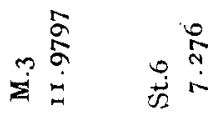
范定 萬

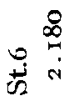

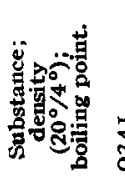
离戠莺

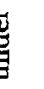

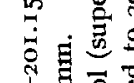

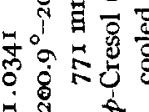
音 宅

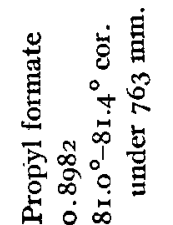

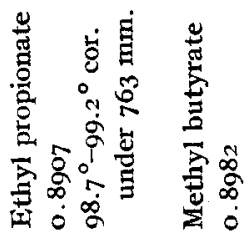
楁兽 ลิ $\stackrel{\infty}{\sim}$ ลิ 요 $\bar{m}$ लै 


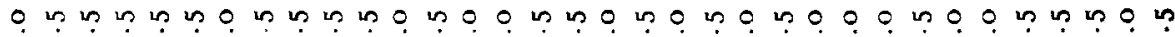

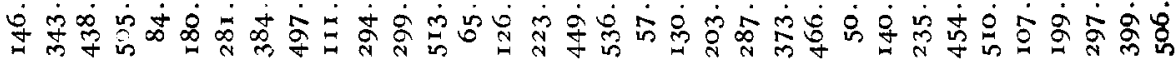

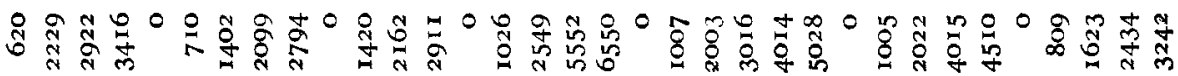

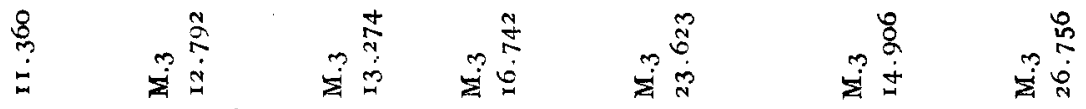

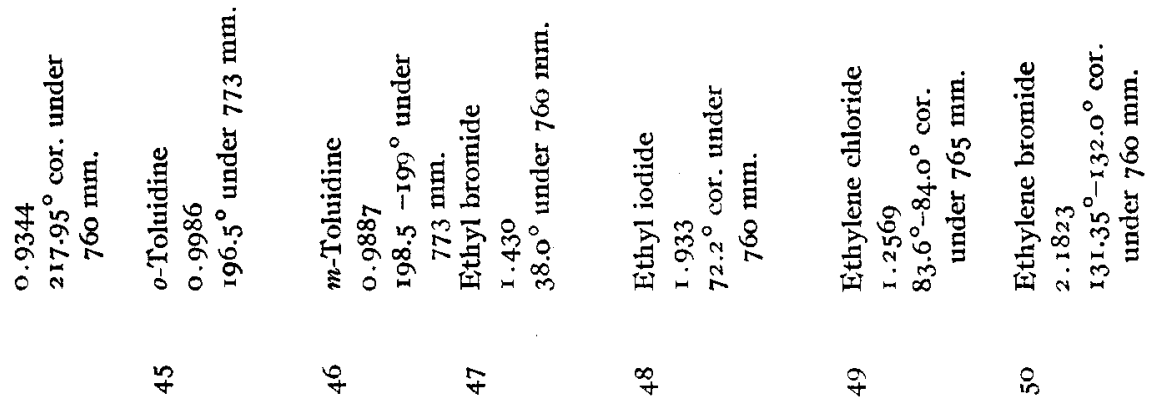

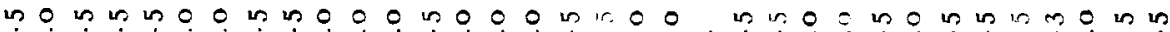

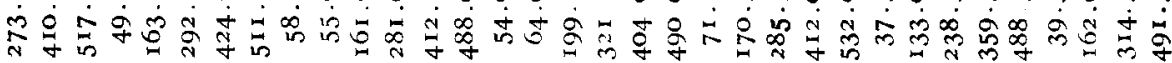

Бี

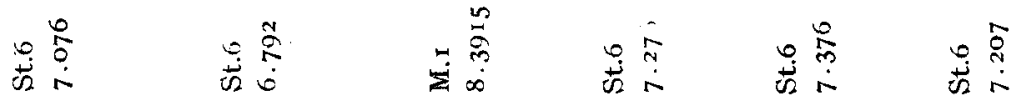

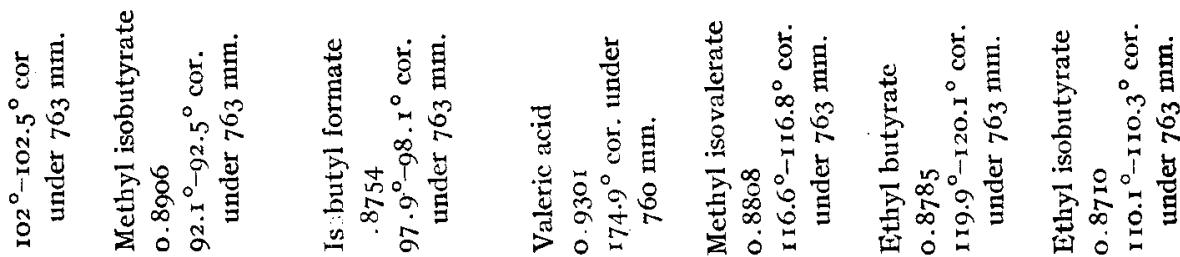

$m$

$\dot{\vec{H}}$

$m$

$\stackrel{\infty}{\infty}$

5

$\infty$ 
988 T. W. RICHARDS, W. N. STULL, J. H. MATHEWS AND C. L. SPEYERS.

are exactly identical at 150 atmospheres. Moreover, bromoform and water have almost the same compressibility, and yet the change of this compressibility with the pressure is noticeably different. Such differences as this must be referred to the specific natures of the component elements, and the internal pressure relations within each substance."

Let us see if the outcomes of the data given above bear out this conclusion. The following table contains the results, for the pressure ranges I00-300 and 300-500, calculated in terms of the rational standard of pressure, namely, the megabar or the megadyne per square centimeter (equals I.org8 kg. per square centimeter or $0.987 \mathrm{~atm}$.). Four series taken from the series of 1903 -namely, those for chloroform, bromoform, carbon tetrachloride and bromine-are included in the table, after having been corrected for the error of gage A; and the compressibility of mercury, as computed from the results of Bridgman is likewise given. Besides the results for compressibility there are recorded two further columns of figures derived from them, namely, in the fourth column of numbers in the table, the difference between the compressibility over the range IO0-300 and that over the range 300-500; and in the fifth column of figures a nearly constant quantity obtained by dividing 10,000 times the figures in the fourth column by that in the second, raised to the 2.05 power. This quotient is nearly constant with similar compounds, even of widely different molecular weight. The exact exponent 2.05 was first found from the extremes of the series, hexane and mercury; subsequently, this value was discovered to be that most generally applicable to the other cases also.

RESULTS.

\begin{tabular}{|c|c|c|c|c|c|}
\hline & $\underset{\text { in }}{\text { Compre }}$ & $\begin{array}{l}\text { RESU } \\
\text { ility }(\beta) \times \\
\text { is of mega }\end{array}$ & $\begin{array}{l}15 . \\
\text { at } 20^{\circ} \\
\text { ars. }\end{array}$ & Difference & \\
\hline & $\begin{array}{l}\text { Between } \\
100-500 .\end{array}$ & $\begin{array}{l}\text { Between } \\
100-300 .\end{array}$ & $\begin{array}{l}\text { Between } \\
300-500 .\end{array}$ & $\begin{array}{c}\text { last two } \\
\text { columins }=\Delta .\end{array}$ & $\frac{10,000 \Delta}{\left(\beta_{100} \cdot 300 \times 10^{8}\right)^{2 \cdot 05}}$. \\
\hline Hexane. . . . . . . . . & $104 \cdot 4$ & I $17 \cdot 5$ & $9 \mathrm{I} .4$ & 26. I & I5 \\
\hline Isohexane. . . . . . . . . & 106.0 & I I 9.0 & 93.0 & 260 & 15 \\
\hline Normal octane........ & $87 \cdot 9$ & $97 \cdot 5$ & $78 \cdot 3$ & 19.2 & I5 \\
\hline Monemethyl-2-heptane. & $91 \cdot 3$ & 100.9 & $8 \mathrm{I} \cdot 7$ & 19.2 & I5 \\
\hline Disopropylethane..... & 94.6 & $104 \cdot 7$ & $84 \cdot 5$ & 20.2 & I 5 \\
\hline Monoethyl-3-hexane.... & 87.0 & 9.0 & 78.0 & 180 & 16 \\
\hline Dimethyl-3,4-hexane. . . & $84 \cdot 4$ & $4 \cdot 5$ & $74 \cdot 3$ & 20.2 & I8 \\
\hline Benzene. . . . . . . . . . & 72.4 & $77 \cdot 3$ & $67 \cdot 5$ & 98 & 14 \\
\hline Toluene............ & 69.0 & 74.1 & 63.9 & 0.2 & 15 \\
\hline Orthoxylene. ......... & $6 \mathrm{I} . \mathrm{I}$ & 65.6 & 566 & 9.0 & 16 \\
\hline Metaxylene........... & 64.8 & $69 \cdot 5$ & 60.1 & $9 \cdot 4$ & I 5 \\
\hline Paraxylene. . . . . . . . & 66.8 & $7 \mathrm{I} \cdot 7$ & $6 I \cdot 9$ & 9.8 & 15 \\
\hline Ethylbenzene . . . . . & $65 \cdot 3$ & 70.1 & $60 \cdot 5$ & 9.6 & 18 \\
\hline Water.............. & $42 . I$ & $43 \cdot 3$ & 40.9 & 2.4 & - II \\
\hline Methyl alcohol......... & $87 \cdot 4$ & 95.2 & 79.6 & I5. 6 & I5 \\
\hline Normal propyl alcohol. & $72 \cdot 3$ & $77 \cdot 3$ & $67 \cdot 3$ & 10.0 & 14 \\
\hline Normal butyl alcohol. . & 70.2 & 76.5 & 63.9 & 12.6 & 18 \\
\hline
\end{tabular}


RESULTS (continued). Compressibility $(\beta) \times 10^{\circ}$ at $20^{\circ}$ $\begin{array}{lll}\text { Between } & \text { Between } & \text { Between } \\ \text { 100-500. } & 100-300 . \quad 300-500 .\end{array}$

Isobutyl alcohol...... 72.2

Tertiary butyl alcohol. . 79.6

Isoamyl alcohol: ...... 76.9

Benzyl alcohol........ 40.7

Glycol............. 32.

Orthocresol......... 43.1

Metacresol......... 43.5

Paracresol.......... 43.1

Methyl acetate....... 80.4

Propyl formate....... 79.5

Ethyl acetate....... 82.8

Ethyl propionate...... 80.0

Methylbutyrate...... 76.8

Methyl isobutyrate.... 81.4

Isobutyl formate..... 79.0

Valeric acid......... 70.5

Methyl isovalerate.... 77.3

Ethyl butyrate...... 78.2

Ethyl isobutyrate..... 82.4

Isobutyl acetate..... 79.6

Isoamyl formate..... 74.0

Methylaniline........ 42.7

Dimethylaniline....... 48.4

Ethylaniline......... 47.I

Diethylaniline....... 50.7

Orthotoluidine....... $4 \mathrm{I} .4$

Metatoluidine....... 42.7

Ethyl bromide....... 90.7

Ethyl iodide........ 75.2

Ethylene chloride..... 62.6

Ethylene bromide..... 5 I. 6

Carbon tetrachloride... 79.5

Chloroform......... 76.4

Bromoform......... 43.2

Bromine......... 53.2

Mercury.......... 3.98
80.8

89.4

84.3

43.3

33.6

44.2

$45 \cdot 5$

$44 \cdot 4$

87.5

86.8

90.2

87.5

84.0

88.7

85.6

76.7

84.4

85.0

89.9

86.9

80 . I

44.9

51.8

49.6

53.9

43.7

44.9

99.8

81.0

67.5

$54 \cdot 3$

85.6

83.0

45.0

$55 \cdot 5$

3.990

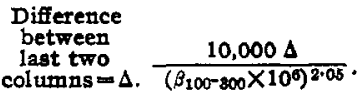

63.6

9.8

69.5

$38 \mathrm{I}$

31.6

42 .

41 . :

41.8

$73 \cdot 3$

72.1

$75 \cdot 4$

72.5

69.6

74.0

72.4

64.4

70.2

71 .

74.9

72.3

67.8

40.5

45.0

44.6

$47 \cdot 5$

39.1

40.5

8I. 6

$69 .+$

57.7

49.0

73.4

69.7

41.4

50.8

3.966
17.2

19.6

14.8

4.9

2.0

$2 . I$

4.0

2.6

14.2

I 4.7

14.8

I 5.0

I 4.4

I 4.7

I 3.2

I 2.3

14. $2^{\prime}$

13.6

I 5.0

4.6

12.3

4.4

6.8

5.0

6.4

4.6

4.4

I 8.2

I I . 6

9.8

$5 \cdot 3$

I 2.2

13.3

3.6

4. 7

0.024
20

I9

I6

20

15

IO

I 6

12

I5

I5

I5

I 6

I5

I 5

15

I 6

I 5

I 5

15

I5

15

I 8

20

I 7

I 8

I9

I 8

14

I 5

I 7

I5

I 3

I5

I5

14

I 5

Inspection of the table shows at once that the statement quoted above is wholly justified and does not need modification, except to define as nearly as possible the quantitative relationship. In general, it is clear that the greater the compressibility, the greater is its decrease with increasing pressure. This holds true especially with similar compounds, and speaking very roughly, it is evident that in the equation $\Delta \times 10^{4}=$ $k\left(\beta \times 10^{6}\right)^{2.05}$ with hydrocarbons and esters $k$, given in the last column, averages about 15 ; with monatomic alcohols and amino compounds with more than three atoms of carbon it averages about 18 . Water, 
990 T. W. RICHARDS, W. N. STULL, J. H. MATHEWS AND C. L. SPEYERS.

and $o$ - and $m$-cresol give much lower values, about I I. If all the compounds be averaged together regardless of their nature, $k$ is very nearly 15 , a value which corresponds to the curve in the accompanying diagram,

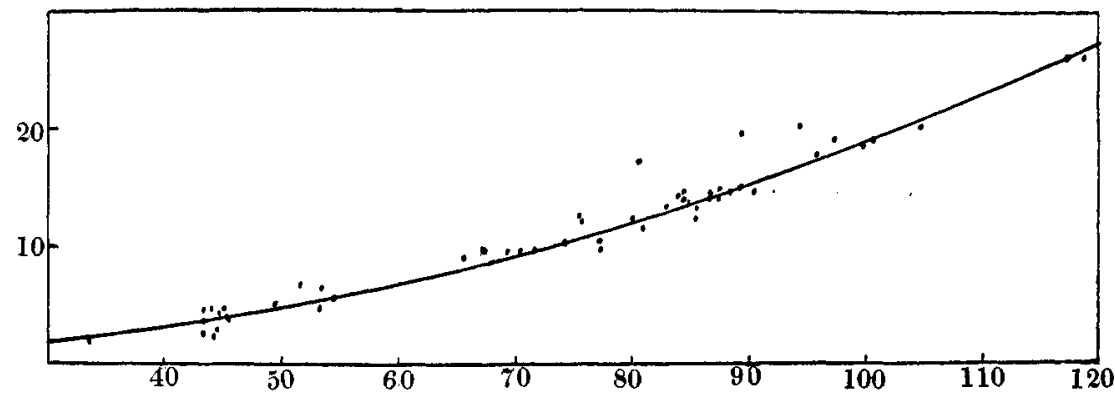

Fig. 3.-The relation of compressibility to its decrease under pressure. Compressibilities are plotted as abscissas and decreases of compressibility due to a definit increase of pressure are plotted as ordinates. Each spot indicates one of the preceding substances; the line depicts the empirical rule described in the text.

where each individual relationship is represented by a point. Here the compressibilities are plotted from left to right in the direction of abscissae and the changes in compressibilities between the pressure ranges 100-300 and 300-500 are plotted vertically. This diagram demonstrates at once both the general proposition that substances with the greatest compressibility usually have the greatest decrease in compressibility with pressure, and also the fact that this rule is only an approximate one, some of the cases being rather widely divergent. It is possible that some of the deviations are due to experimental error, but the fact that the substances of a given type such as the amiaes seem all to deviate in the same way makes it likely that the nature of the substances really affects this tendency.

Doubtless the different groups of substances differ not only in the value of the quantity $k$ but also as to the exponent in the equation, or perhaps in the introduction of some other terms. For example, in the "monatomic" alcohols there seems to be a distinct if somewhat irregular rise in the value $k$, from I5 with methyl alcohol to 20 with benzyl alcohol, as the molecular weight increases. It is interesting to note in this connection that another volume property of alcohols, namely, their molecular volume at the boiling point, likewise deviates from Kopp's additive law more than with most other compounds. That a connection exists between these phenomena is not improbable. An effect of this sort is not to be observed in the case of the esters, where methyl acetate gives the same value 15.0 as isoamyl formate and no large deviation occurs between. Moreover, the average of the five octanes gives almost exactly the same value (15.4) as the two hexanes, 15 . 
The solid metals, cesium, potassium, and sodium, also fall in approximately with the other results, at least showing deviations of about the same order of magnitude, as already indicated in a previous publication, where the following statement is made: ${ }^{1}$

"The data given are enough to show that the five alkali metals are no exceptions to the usual but not universal rule that the more compressible a substance, the more its compressibility decreases with increasing pressure. It is interesting to note also, that cesium, having a compressibility of about the order of such liquids as bromine and chloroform, should have its compressibility change with pressure to an extent not very different from these liquids."

From the point of view of the theory of compressible atoms this general relationship is exactly what one would expect.

When a substance is already under great pressure, each small addition of pressure will be but an unimportant percentage of the whole, and, therefore, each like addition would be expected to have nearly the same effect on the volume. On the other hand, if a substance is under a small pressure, a small further addition to the pressure will cause a great percentage of change in the volume, but a second addition of an equally small amount will be a much smaller percentage of the whole, and, therefore, would be expected to have a greatly diminished effect on the volume. As an example, the effect of pressure on a gas may be cited. When a gas is under atmospheric pressure, the addition of, one atmosphere's pressure halves its volume, the compressibility is 0.5 . The addition of another atmosphere's pressure contracts the volume to two-thirds of this half; hence, the compressibility during this step is only o.17. The next atmosphere's pressure contracts the gas to three-quarters of its last value; the compressibility, therefore, during this next stage will be only 0.08 of the original volume. Thus, the very large compressibility of a gas falls off enormously in magnitude as the pressure increases, whenever the gas is at first under only a slight pressure. If, on the other hand, the gas starts under a pressure of one hundred atmospheres, and another atmosphere's pressure is added to this, the compressibility will appear to be about 0.0099 , provided that Boyle's law is assumed to hold exactly. The next atmosphere's pressure will cause this value to be about 0.0097 , and the next not far from 0.0095 . Thus a gas under great pressure has its compressibility diminished only very slightly as the pressure increases. The same qualitative principle would obviously apply also in cases where the compressibility obeyed a law very different from that of Boyle. For example; if the law were $v p^{2}=k$, the compressibilities on two successive additions of one atmosphere's pressure would be 0.020 and 0.019 , respectively.

${ }^{1}$ Carnegie Institution of Washington, Publication 76, 24 (1907). 
The theory of compressible atoms assumes that solids and liquids are very different from gases in that they are supposed to be under great internal pressure, due to their own cohesion, but there is no reason why this internal pressure should not have the same effect as that just described. Thus, as shown above, it is reasonable to suppose that those substances which have the least compressibility should also have this compressibility fall off only very slightly with the pressure. Slight compressibility should go hand in hand with its slight decrease with increasing pressure.

This is just what is actually observed and tabulated above in the diagram, which thus becomes a distinct confirmation of one of the fundamental postulates of the theory of compressible atoms. The data show that the less compressible substances act exactly as if they were under great internal pressure, and as if this great pressure were the determining agent in fixing their volume.

It is not surprising that the peculiar nature of the elements constituting a compound should cause slight but consistent deviations from the general rule, as for example in the case of the amines tabulated above. One has no right to assume that all the elements in combination should have precisely the same changes in compressibility under similar conditions. In order to find the closest compliance with the rule, one should naturally compare homologous compounds. This prediction also is seen to be verified by the comparison of the figures given in the table. In homologous series the consistency is often remarkable; and the more nearly the similarity of structure the more striking is the agreement, as in the case of the xylenes. Orthoxylene, with an average compressibility of 6I.I over the whole range, falls off 9.0 between the first and second halves of the range. The corresponding figures for $m$-xylene are 64.8 and 9.4 , and the corresponding figures for $p$-xylene are 66.8 and 9.8 . Evidently the increase of second differential quotient keeps pace steadily with the compressibility itself. Those who are interested will find many other similar cases in the table, although none are quite so fitted by similarity of nature for a basis of comparison as this particular series. Such exceptions as appear are probably due to the special effects of special elements or of special structures; but the exceptions are not plentiful or glaring enough to hide the general tendency of the points to group themselves in the neighborhood of the curve which defines the strict application of the general principle.

Thanks are due to the Carnegie Institution of Washington for generous pecuniary assistance extended over a number of years. This help alone has made possible the investigation, which was begun in 1904 and is still being continued. 


\section{Summary.}

In this paper are described careful determinations of the compressibilities of certain liquid hydrocarbons, alcohols, amines, esters, and organic halides. The results, taken in connection with several others previously published, are tabulated in such a way as to show that in general the greater the compressibility of a substance, the greater is its decrease with increasing pressure. Further, it is pointed out that this very general rule is just what one might predict from the theory of compressible atoms. The new data will shortly be compared, in a following paper, with many other physical properties of the liquids in question.

HARVARD UNIVERSITY, 1904-1911.

[Publication of the Research Laboratory of Physical Chemistry, MassaChusetts Institute of TechNology, Boston, Mass., No. 84.]

\section{THE EQUILIBRIUM BETWEEN AMMONIUM CARBONATE AND AMMONIUM CARBAMATE IN AQUEOUS SOLUTION AT $25^{\circ}$.}

BY GzORGE H. BURROWS AND GILBERT N. LEWTS.

Received June 13, 1912.

The substance known as carbamic acid, $\mathrm{NH}_{2} \mathrm{COOH}$, although hitherto little studied, is interesting not only because it is the first member of an important series of organic acids, but also because its ammonium salt always occurs in considerable amount in aqueous solutions of ammonium carbonate. The determination of the equilibrium in such solutions is an important step in the investigation of the properties of carbamic acid.

In the year 1885 , Fenton ${ }^{1}$ made measurements on this equilibrium, his method of analysis being based on the difference in action of alkalin hypochlorite and hypobromite solutions toward ammonium and amino groups, previous experiments ${ }^{2}$ having shown that the hypochlorite solution liberates nitrogen from ammonium groups only, while sodium hypobromite acts on both ammonium and amino groups. In the present case, however, owing to the rapidity with which the carbamate and carbonate are transformed into one another under ordinary conditions, it appeared unlikely that the results obtained by Fenton could have much more than qualitative significance. A determination by some other method of analysis seemed therefore desirable.

It is well known that solutions of calcium or of barium salts do not produce precipitates in freshly prepared solutions of ammonium carbamate, but that the mixtures become turbid on standing for a short time at room temperature, and, if kept neutral or slightly alkalin, precipitation as carbonate is soon completed. A series of experiments involving the precipitation and determination together of the carbonate and carbamate by addition of cold barium hydroxide solution drew at-

1 Proc. Roy. Soc. London, 39, 386 (1885).

J. Chem. Soc., 35, 12 (1879). 